\title{
Tuberculosis primaria de esófago: reporte de caso
}

\author{
Rosmeri Vengoa Humpire* ${ }^{\text {a }}$; Karina Ivonne Orihuela Lazo ${ }^{2 b}$; Humberto Liu Bejarano ${ }^{3 c}$; Luis Fernando Barreda Bolaños ${ }^{30}$
}

RESUMEN

Mujer de 60 años, natural de Tarma y procedente de Lima, con antecedentes de exposición a biomasas, contacto con paciente con tuberculosis, hipertensión arterial, arritmia cardiaca, y madre con cáncer de ovario. La paciente acude a consulta con un cuadro de siete meses de evolución caracterizado por disfagia progresiva, pérdida de peso de 15 kilogramos y fiebre vespertina. En la endoscopía previa mostró un tumor esofágico, y la tomografía reveló un engrosamiento tumoral a nivel de los tercios medio y distal del esófago, dependiente de la pared, y adenopatías mediastinales de 10x10 mm. Los demás órganos torácicos y abdominales no muestran alteraciones. En la última endoscopía se encuentra una lesión ulcerada en esófago y en el estudio patológico se observó una extensa inflamación crónica granulomatosa con células gigantes y necrosis; la prueba de Ziehl Neelsen para el bacilo de Koch (BK) fue negativa sin evidencia de lesión maligna y la reacción en cadena de la polimerasa (PCR) fue positiva para Mycobacterium. Se tomó una biopsia de las adenopatías mediante una ecoendoscopía, con una PCR negativa para Mycobacterium. Concluimos que el cuadro fue una tuberculosis esofágica primaria, y se inició el tratamiento con el esquema específico sensible a una dosis ajustada por peso.

Palabras clave: Tuberculosis; Esófago; PCR; Mycobacterium; Endoscopía (Fuente: DeCS BIREME).

\section{Primary esophageal tuberculosis: a case report}

\section{ABSTRACT}

A 60-year-old woman born in Tarma and living in Lima, with a history of biomass exposure, contact with a patient with tuberculosis, arterial hypertension, heart arrhythmia and mother with ovarian cancer, visited the medical center with progressive dysphagia, 15-kilogram weight loss and evening fever for seven months. A previous endoscopy revealed an esophageal tumor. A CT scan showed middle and distal third esophageal wall thickening, and 10x10 mm mediastinal adenopathies. The rest of the thoracic and abdominal organs were normal. The last endoscopy revealed an ulcerated lesion in the esophagus. The pathological evaluation showed a large chronic granulomatous inflammation with giant cells and necrosis. Ziehl-Neelsen stain was negative for Koch bacillus and revealed no malignant lesion. A Mycobacterium tuberculosis-positive polymerase chain reaction (PCR) was observed. An adenopathy biopsy was performed by endoscopic ultrasound and PCR outcome was negative for Mycobacterium tuberculosis. In conclusion, primary esophageal tuberculosis was diagnosed and a specific treatment with a weight-adjusted dose was initiated.

Keywords: Tuberculosis; Esophagus; Polymerase chain reaction; Mycobacterium; Endoscopy (Source: MeSH NLM).

1 Hospital Nacional Hipólito Unanue, Servicio de Gastroenterología. Lima, Perú.

2 Hospital Central de La Fuerza Aérea del Perú, Servicio de Gastroenterología. Lima, Perú.

3 Instituto Nacional de Enfermedades Neoplásicas, Servicio de Gastroenterología. Lima, Perú.

a Ex Residente del Hospital Nacional Hipólito Unanue.

b Ex Residente del Hospital Central de La Fuerza Aérea del Perú.

c Médico Asistente.

d Director de Especialidades Médicas.

*Autor corresponsal. 


\section{INTRODUCCIÓN}

La tuberculosis esofágica (TE) es una enfermedad rara, tanto en personas inmunocomprometidas como en inmunocompetentes, y representa el 2,8 \% de todos los casos de tuberculosis gastrointestinales ${ }^{(1,2)}$. El primer caso de TE, un diagnóstico post mortem, se remonta a 1890; mientras que en 1907 fue reportado el primer caso ante mortem ${ }^{(3)}$. En 1913, una serie de autopsias demostraron una afección secundaria del esófago en solo $25(0,15 \%)$ de 16489 pacientes que murieron de tuberculosis ${ }^{(4)}$. En el Perú, Chahud ${ }^{(5)}$ reportó solo un caso en un grupo de 202 personas con tuberculosis digestiva; por otra parte, Yriberry encontró solo el 1,7\% de tuberculosis esofágicas en un estudio de 58 casos de tuberculosis digestiva ${ }^{(6)}$. Chávez y Malca reportaron sendos casos de tuberculosis en los hospitales Loayza y Guillermo Almenara Irigoyen, respectivamente ${ }^{(7)}$.

La tuberculosis esofágica puede ser primaria o secundaria. La TE primaria es rara y está definida por el compromiso único del esófago, sin la alteración de otro tejido del organismo. Su baja incidencia se debe a ciertos factores protectores del esófago, como el epitelio escamoso estratificado, la peristalsis esofágica, la cubierta de moco, la deglución de saliva y la postura erecta (2).

La TB esofágica secundaria es la más común y aparece, por lo general, como consecuencia de una tuberculosis linfoide, la cual se divide en cuatro etapas. En la primera se observan una hiperplasia linfoide, nódulos y formación de granulomas. En la segunda etapa, ocurre la necrosis caseosa. En la tercera fase, la capa adventicia de los ganglios linfáticos se rompe, y luego estos ganglios se adhieren y se fusionan. En la etapa final, la materia caseosa se dispersa y se forma una cavidad. En la segunda y tercera etapas, las adenopatías mediastinales dañan el tejido esofágico ${ }^{\left({ }^{8}\right)}$.

Se han descrito tres tipos de lesiones en el esófago: ulcerativas, hiperplásicas y granulares. El tipo ulcerativo está caracterizado por lesiones superficiales con bordes irregulares y una base gris que comprometen la mucosa y submucosa, son de tamaño variable y pueden ser simples o múltiples. El segundo tipo es el hiperplásico, estas lesiones son una respuesta fibrótica a la inflamación crónica, aparecen en toda la pared esofágica y, a veces, en el tejido mediastinal, lo que estrecha la luz del órgano. El tipo granular es el más inusual, las lesiones son pequeños gránulos grisáceos que pueden ser verrugosos y engrosados ${ }^{(9)}$.

\section{CASO CLÍNICO}

Mujer de 60 años con antecedentes de exposición a biomasas, hipertensión arterial y arritmia cardiaca. Refiere contacto con un paciente tuberculoso. Como antecedente familiar señala que su madre tuvo cáncer de ovario. Acude al Instituto Nacional de Enfermedades Neoplasicas (INEN) con un cuadro de siete meses de evolución. Presenta disfagia progresiva, fiebres vespertinas y pérdida de peso de 15 kilogramos, y es asintomática respiratoria. Previamente, en otra institución de salud se le realizaron tres endoscopías que mostraron una lesión submucosa, y biopsias no diagnósticas.

Exámenes auxiliares: hemoglobina: $11,1 \mathrm{gr} / \mathrm{dl}$; hematocrito: 33,4; plaquetas: 402 000; leucocitos: 6600; linfocitos: 44000 ; monocitos: 4000; neutrófilos: 49 000; Elisa VIH 1 y 2: negativos; HTLV-1: negativo.

La tomografía muestra un engrosamiento tumoral a nivel de los tercios medio y distal del esófago y adenopatías mediastinales de $10 \times 10 \mathrm{~mm}$, aproximadamente; en el tórax son visibles unas bronquiectasias secuelares, y en el abdomen no hay alteraciones. En la radiografía de esófago a doble contraste se observa una lesión por defecto de relleno con contornos definidos en el tercio medio del esófago, a $28 \mathrm{~cm}$ de la arcada dentaria, de extensión aproximada de $3,5 \mathrm{~cm}$ de largo, que parece dependiente de la pared esofágica. La endoscopía reporta una lesión redondeada de aspecto submucoso con superficie ulcerada, de bordes netos, cubierta por fibrina blanquecina que mide $25 \times 35 \mathrm{~mm}$, aproximadamente, y ocupa más del $50 \%$ del lumen esofágico, ubicada entre 25 a $30 \mathrm{~cm}$ de la arcada dentaria. La biopsia de esta lesión se observa en la figura 1. 

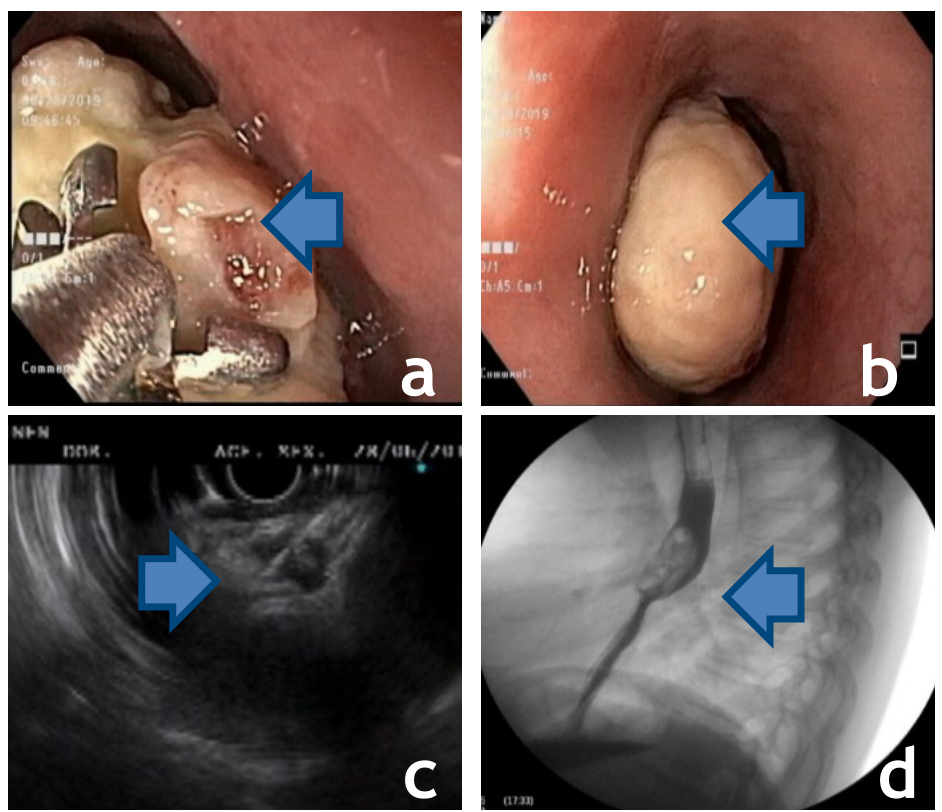

Figura 1. Lesión esofágica vista en endoscopía, ultrasonografía endoscópica (EUS) y radiografía baritada de esófago: a) Biopsia en lecho ulceroso, b) lesión de aspecto subepitelial, c) adenopatías mediastinales con punción aspirativa con aguja fina (PAAF) por ultrasonografía endoscópica (EUS), y d) radiografía baritada de esófago con lesión intraluminal. (Las flechas muestran el sitio de la lesión)

El reporte de anatomía patológica describe un fragmento de tejido conectivo con extensa inflamación crónica granulomatosa y presencia de células gigantes y necrosis. Inmunohistoquimica: CD68, destacan los histiocitos epitelioides. Tinción de Ziehl Neelsen: negativo para BK. PCR para Mycobacterium : positivo, sensible para isoniacida (Figura 2).
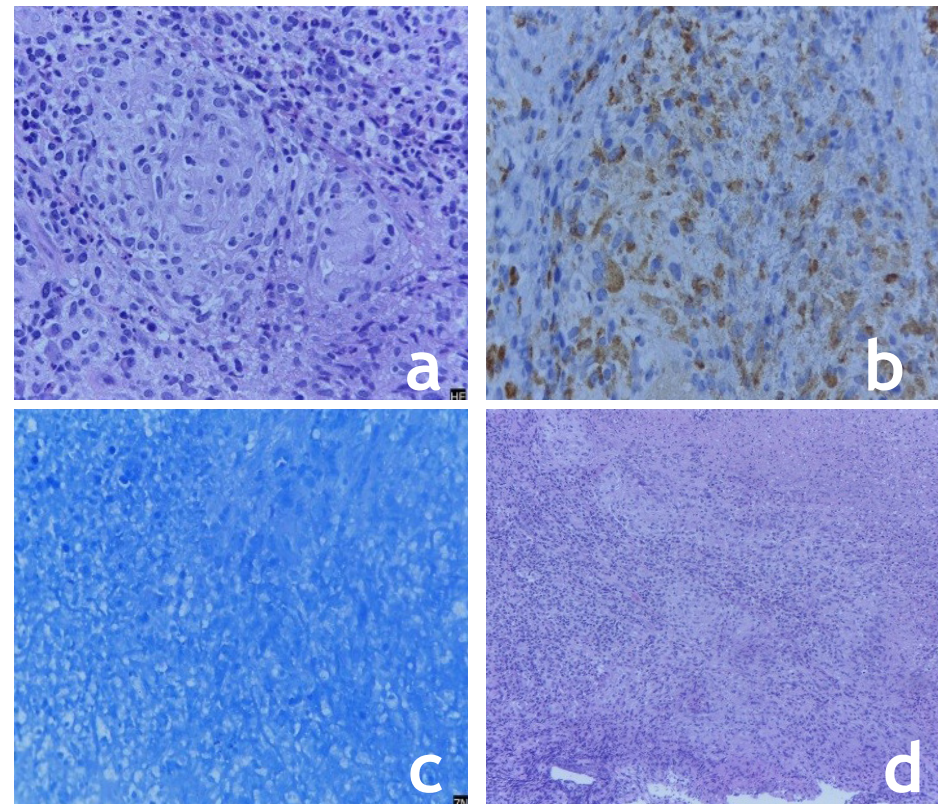

Figura 2. Tinción de hematoxilina eosina, inmunohistoquímica de anticuerpos CD68 y Ziehl-Neelsen de adenopatias mediastinales. a)Tinción por hematoxilina eosina ( $\mathrm{HE})$ 50x, b) Tinción por inmunohistoquímica de anticuerpos CD68 c) Tinción por Ziehl-Neelsen d) Tinción por HE 10x 
Rosmeri Vengoa Humpire; Karina Ivonne Orihuela Lazo; Humberto Liu Bejarano; Luis Fernando Barreda Bolaños

En la ecoendoscopía se observa una lesión dependiente de la pared del esófago que no sobrepasa la adventicia y tres adenopatías mediastinales, entre el cayado aórtico y la arteria pulmonar, de aspecto inflamatorio típico, la mayor de $10 \mathrm{~mm}$. Se realizó la punción aspirativa con aguja fina (PAAF) de dos de ellas con aguja de punción de $22 \mathrm{G}$. y aspiración de $5 \mathrm{cc}$ de aire, cuyos posteriores análisis de PCR para detectar presencia de Mycobacterium fueron negativos.

Con el diagnóstico de tuberculosis de esófago con frotis negativo y PCR positiva sensible a rifampicina, se inicia el esquema sensible a dosis ajustadas por peso con 3 tabletas de isoniacida de $100 \mathrm{mg}, 3$ tabletas de etambutol de $400 \mathrm{mg}, 3$ tabletas de pirazinamida de $500 \mathrm{mg}$ y 2 tabletas de rifampicina de $300 \mathrm{mg}$. La paciente ha culminado el tratamiento de 6 meses sin complicaciones. Respecto a los controles, la tomografía demuestra una mejoría de la lesión de esófago, y las tres baciloscopias de esputo han sido negativas.

\section{DISCUSIÓN}

Los síntomas clínicos asociados con la TE son diversos, e incluyen manifestaciones sistémicas (pérdida de peso, fiebre vespertina, escalofríos y malestar) y locales (dolor torácico anterior, disfagia y tos) ${ }^{(10,11)}$. Además, se han notificado algunos casos de sangrado por una fístula aortoesofágica ${ }^{(12)}$, y en ocasiones, la tos, la disnea y la fiebre alta pueden relacionarse con una fístula bronco-esofágica ${ }^{(13)}$. La disfagia, que es el síntoma más frecuente, está ocasionada por una afectación intrínseca de la pared esofágica: una compresión del esófago inducida por los ganglios linfáticos mediastínicos, además de una fibrosis mediastínica que puede producir compresión y alterar la motilidad esofágica; el lugar más comprometido es el tercio medio sobre la bifurcación traqueal.

El diagnóstico de la TE está basado en la radiología, endoscopía, histología y en la respuesta a la medicación antituberculosa. Las características radiológicas de la TE pueden incluir cambios no específicos asociados con lesiones linfáticas u órganos contiguos. La tomografía de tórax puede ayudar a identificar lesiones pulmonares, lesiones linfáticas y complicaciones como una fístula broncoesofágica ${ }^{(14)}$. Sin embargo, debido a que las características radiológicas de la TE son similares al cáncer de esófago, la linfadenitis tuberculosa y las metástasis ganglionares malignas, es difícil diferenciarla de otras enfermedades solo con el hallazgo radiológico.

La endoscopía puede ser útil para el diagnóstico y el seguimiento de la enfermedad. La lesión más común es una úlcera tuberculosa, con una base grisácea y un borde infiltrado irregularmente; además, la TE puede presentarse como una lesión proliferativa estenosante, y puede confundirse fácilmente con una neoplasia ${ }^{(14,15)}$.
Aunque varios autores reportan lesiones submucosas con más frecuencia, por lo general, predominan las lesiones ulceradas.

En la TE primaria, la lesión esofágica inicial es de tipo subepitelial que, eventualmente, se ulcera en la zona apical y se convierte en una lesión hiperplásica o granular debido a la inflamación crónica persistente ${ }^{(17)}$.

Para confirmar el diagnóstico TE es necesario el aislamiento de los bacilos tuberculosos (18). Gordon y Marshall (19) informaron que la tinción de Ziehl-Neelsen y el cultivo de muestras de biopsia fueron útiles para realizar el diagnóstico correcto de TE. Por lo general, la histopatología de las muestras de biopsia esofágica muestra granulomas epitelioides y células gigantes multinucleadas del tipo de Langhans. Si bien los granulomas con necrosis caseosa sugieren una tuberculosis, existen otras enfermedades que pueden presentarse con inflamación granulomatosa: la enfermedad de Crohn, una infección fúngica, la sífilis y la sarcoidosis ${ }^{(16,20)}$.

La densidad bacteriana en los granulomas del tejido infectado suele ser baja. Además, estos se ubican en la capa submucosa del esófago, por lo que las biopsias endoscópicas no suelen ser útiles, lo que destaca la necesidad de muestras de tejido múltiples y profundas. Según la literatura, la sensibilidad para la detección histopatológica en granulomas caseificados, por este método, varía del $25 \%$ a 60,8\% (21).

La detección de ADN de micobacterias mediante PCR es una técnica rápida (permite obtener un diagnóstico de 1 a 3 días) y altamente eficaz. Este método amplifica la molécula de ADN y detecta la presencia de menos de 10 bacilos de una muestra (a partir de homogeneizados de tejidos, esputos y aspirados de líquidos), aunque no distingue bacilos vivos de los muertos, es decir, TBC activa de inactiva. Tiene una sensibilidad variable ( $27 \%-81 \%$ ) y una alta especificidad (67\%-100\%) en el diagnóstico de TBC extra pulmonar ${ }^{(22) .}$

Las lesiones de TE estudiadas por ultrasonido endoscópico (EUS) son descritas como masas hipoecoicas heterogéneas u homogéneas en la pared esofágica, con interrupción de la adventicia esofágica y linfadenitis mediastínica. Sin embargo, a diferencia de los tumores submucosos (como el tumor estromal o el leiomioma), la mayoría de las lesiones tuberculosas tienen manchas y líneas hiperecoicas en el parénquima que pueden afectar a toda la pared del esófago ${ }^{(17)}$.

La aspiración con aguja fina guiada por ultrasonido (EUS/FNA, del inglés Endoscopic Ultrasound /Fine Needle Aspiration) es muy utilizada para obtener tejido de lugares profundos. Por lo general, para las úlceras, la biopsia endoscópica puede obtener un tejido de diagnóstico valioso, pero en 
las lesiones que se presentan como un tumor submucoso, la sensibilidad de esta prueba convencional es baja. En estos casos, las EUS-FNA es una herramienta útil porque puede obtener la biopsia tanto de la lesión como de los ganglios linfáticos adyacentes. Asimismo, se puede incluir la prueba de PCR para micobacteria para mejorar el rendimiento diagnóstico ${ }^{(17)}$.

Este caso es relevante debido a la poca frecuencia con que se presenta una TE y a que ha simulado una neoplasia submucosa de esófago. Además, ha sido evidente la evolución endoscópica de la lesión, de submucosa a ulcerativa, de manera espontánea, tal como está reportado en la literatura. El método diagnóstico usado fue la biopsia endoscópica del lecho ulceroso, con resultados histológicos característicos de tuberculosis, pero con BK negativo, lo cual también se ha descrito para las células paucibacilares, por lo que el diagnóstico final requirió de la prueba de PCR para Mycobacterium, la cual confirmó la etiología infecciosa.

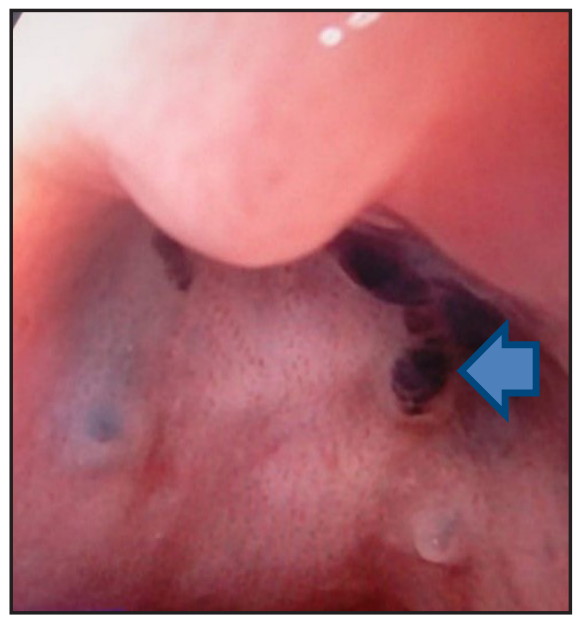

Concluimos que este caso corresponde a una tuberculosis esofágica primaria (enfermedad poco frecuente respecto a la secundaria) debido a que no hallamos otro foco sospechoso (por las imágenes radiológicas) y a que la ecoendoscopía mostró una lesión dependiente de la pared esofágica. Además, encontramos algunos ganglios mediastinales que no mostraron ADN de Mycobacterium tuberculosis en la prueba de PCR.

La paciente retornó al Instituto Nacional de Enfermedades Neoplásicas (INEN), y en su último control médico, al mes de finalizar el tratamiento, se realizó una gastroscopía que evidencia una lesión de aspecto cicatricial blanquecina con áreas hiperpigmentadas de $15 \times 10 \mathrm{~mm}$, aproximadamente, que ocupa el $25 \%$ de la circunferencia esofágica (Figura 3). Las biopsias que se tomaron fueron negativas para bacilos ácido-alcohol-resistentes en tinción de Ziehl-Neelsen. La recuperación clínica y la evolución histológica fueron favorables.

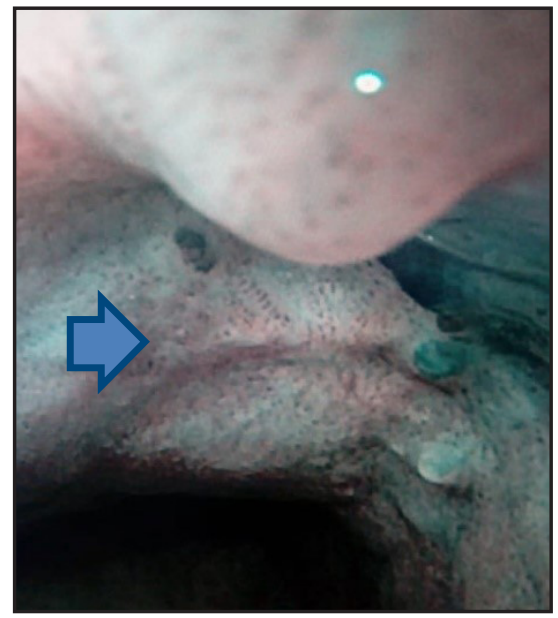

Figura 3. Lesión esofágica vista en la endoscopía (las flechas señalan la lesión)

Fuentes de financiamiento: Este artículo ha sido financiado por los autores.

Conflictos de interés: Los autores declaran no tener ningún conflicto de interés.

\section{REFERENCIAS BIBLIOGRÁFICAS}

1. Patel N, Amarapurkar D, Agal S, Baijal R, Kulshrestha P, Pramanik $S$, et al. Gastrointestinal luminal tuberculosis: establishing the diagnosis. J Gastroenterol Hepatol. 2004; 19(11): 1240-6.

2. Gupta SP, Arora A, Bhargava DK. An unusual presentation of oesophageal tuberculosis. Tuber Lung Dis. 1992; 73(3): 174-6.

3. Fahmy AR, Guindi R, Farid A. Tuberculosis of the oesophagus. Thorax. 1969; 24(2): 254-6.

4. Lockard LB. Esophageal tuberculosis: a critical review. Laryngoscope. 1913; 23(5): 561-84.
5. Chahud Isse A. Digestive tuberculosis. Rev Gastroenterol Peru. 1991; 11(1): 72-89.

6. Yriberry S, Cervera Z, Soriano C, Frisancho O, Machado A, Zumaeta E. Tuberculosis digestiva en el Hospital Nacional Edgardo Rebagliati Martins (HNERM): un estudio retrospectivo de 5 años (1993-1998). Rev Gastroenterol Perú. 1998; 18(3): 238-49.

7. Malca CL, Torreblanca NJ, Asato HC, Velasco ML. Esophageal tuberculosis: case report. Rev Gastroenterol Peru. 2003; 23 (1): 67-9.

8. Liu FG, Pan JX, Wu GG. CT diagnosis of mediastinal lymphnodein adults. Chin Radiol J. 2001; 35: 655-8.

9. Kramer P. Infections of the esophagus. En: Gastroenterology. 3rd edition. W. B. Saunders Company LTD; 1974. p. 329-38.

10. Peixoto PC, Ministro PS, Sadio AD, Cancela EM, Araújo RN, Machado $\mathrm{JL}$, et al. Esophageal tuberculosis: an unusual cause of dysphagia. Gastrointest Endosc. 2009; 69(6): 1173-6.

11. Vahid B, Huda N, Esmaili A. An unusual case of dysphagia and chest pain in a non-HIV patient: esophageal tuberculosis. Am J Med. 2007; 120(4): e1-2. 
Rosmeri Vengoa Humpire; Karina Ivonne Orihuela Lazo; Humberto Liu Bejarano; Luis Fernando Barreda Bolaños

12. O'Leary M, Nollet DJ, Blomberg DJ. Rupture of a tuberculous pseudoaneurysm of the innominate artery into the trachea and esophagus: report of a case and review of the literature. Hum Pathol. 1977; 8(4): 458-67.

13. Wigley FM, Murray HW, Mann RB, Saba GP, Kashima H, Mann JJ. Unusual manifestation of tuberculosis: TE fistula. Am J Med. 1976; 60(2): 310-4.

14. Nagi B, Lal A, Kochhar R, Bhasin DK, Gulati M, Suri S, et al. Imaging of esophageal tuberculosis: a review of 23 cases. Acta Radiol. 2003; 44(3): 329-33.

15. Patnayak R, Reddy MK, Parthasarathy S, Yootla M, Reddy V, Jena A. Unusual presentation of esophageal tuberculosis mimicking malignancy. Saudi J Gastroenterol. 2008; 14(2): 103-4.

16. Fujiwara $\mathrm{Y}$, Osugi H, Takada N, Takemura M, Lee $\mathrm{S}$, Ueno $M$, et al. Esophageal tuberculosis presenting with an appearance similar to that of carcinoma of the esophagus. J Gastroenterol. 2003; 38(5): 477-81.

17. Kang M-J, Yi SY. Esophageal tuberculosis presenting as a submucosal tumor. Clin Gastroenterol Hepatol. 2008; 6(2): A26.

18. Savage PE, Grundy A. Oesophageal tuberculosis: an unusual cause of dysphagia. Br J Radiol. 1984; 57(684): 1153-5.

19. Gordon AH, Marshall JB. Esophageal tuberculosis: definitive diagnosis by endoscopy. Am J Gastroenterol. 1990; 85(2): 174-7.

20. Fujiwara T, Yoshida Y, Yamada S, Kawamata H, Fujimori T, Imawari M. A case of primary esophageal tuberculosis diagnosed by identification of Mycobacteria in paraffin-embedded esophageal biopsy specimens by polymerase chain reaction. J Gastroenterol. 2003; 38(1): 74-8.

21. Welzel TM, Kawan T, Bohle W, Richter GM, Bosse A, Zoller WG. An unusual cause of dysphagia: esophageal tuberculosis. J Gastrointestin Liver Dis. 2010; 19(3): 321-4.

22. Bresky RG, Silva ZN, Madariaga GJ. Esofagitis tuberculosa en un paciente HIV positivo. Rev Med Chil. 2007; 135(10): 1323-6.

\section{Correspondencia:}

Rosmeri Vengoa Humpire

Dirección: Av. Angamos 2520. Lima 34, Perú.

Teléfono: (511)9987885080

Correo electrónico: roussven@gmail.com

Recibido: 21 de agosto de 2019

Evaluado: 06 de enero de 2020

Aprobado: 04 de junio de 2020

(c) La revista. Publicado por Universidad de San Martín de Porres, Perú. (cc) $\mathbf{B r}$ Licencia de Creative Commons Artículo en acceso abierto bajo términos de Licencia Creative Commons Atribución 4.0 Internacional. (http://creativecommons.org/licenses/by/4.0/)

\section{ORCID iDs}

Rosmeri Vengoa Humpire

(ㄱ) https: //orcid.org/0000-0002-6100-5185

Karina Ivonne Orihuela Lazo

Humberto Liu Bejarano

(1) https: //orcid.org/0000-0001-6021-7605

Luis Fernando Barreda Bolaños C https: // orcid.org/0000-0002-7923-6299 